\title{
Proposta de um modelo de referência para o desenvolvimento de produtos do vestuário utilizando impressão 3D
}

\section{Proposal for a reference model for the development of clothing products using 3D printing}

\author{
Nathalia Ruiz Fuchs \\ Universidade Estadual de Maringá \\ nathaliaruizfuchs@ hotmail.com \\ Syntia Lemos Cotrim \\ Universidade Estadual de Maringá \\ slcotrim2@uem.br \\ Gislaine Camila Lapasini Leal \\ Universidade Estadual de Maringá \\ gclleal@uem.br
}

\begin{abstract}
Resumo
O processo de desenvolvimento de produtos tem contribuído para o sucesso de produtos no mercado desde o início de sua criação. Os modelos de referência presentes na literatura auxiliam na organização das etapas e atividades presentes neste processo. Entretanto, quando se trata de uma inovação radical, existe uma dificuldade de adequação a esses modelos. A inovação radical normalmente vem de avanços tecnológicos, de invenções ou da busca por novos mercados. De uma perspectiva mercadológica, a tecnologia de impressão 3D tem sido apontada como uma ruptura em seu modelo de produção atual. A impressão 3D tem se expandido e sua aplicação pode ser visualizada em diversos segmentos, inclusive na indústria da moda. Neste contexto, este artigo propõe um modelo de referência voltado exclusivamente para a impressão 3D de vestuários. $\mathrm{O}$ trabalho também apresenta uma análise crítica de cinco modelos de referência consolidados na literatura, entre os quais dois são generalistas e três são específicos, sendo um mecatrônico e dois voltados para o vestuário. Além disso, para o domínio da tecnologia de impressão 3D realizou-se a modelagem e a impressão tridimensional de um sapato de salto alto.
\end{abstract}

Palavras-chave: Desenvolvimento de Produto; Modelos de Referência; Inovação Radical; Impressão 3D; Indústria do Vestuário.

\footnotetext{
${ }^{*}$ RECEBIDO EM 11/08/2020. ACEITO EM 26/09/2020.
} 


\begin{abstract}
The product development process has contributed to the success of products on the market. The reference models found in the literature help to organize the stages and activities present in this process. However, when it comes to a radical innovation, there is a difficulty in adapting to these models. Radical innovation usually comes from technological advances, from inventions or from the search for new markets. From a marketing perspective, 3D printing technology has been identified as a breakthrough from its current production model. 3D printing has expanded and its application can be viewed in several segments, including the fashion industry. In this context, this article proposes a reference model focused exclusively on 3D printing of clothing. The work also presents a critical analysis of five reference models consolidated in the literature, among which two are generalists, and three are specific, one being mechatronic and two focused on clothing. In addition, for the domain of 3D printing technology, a threedimensional modeling and printing of a high-heeled shoe was carried out.
\end{abstract}

Keywords: Product development; Reference models; Radical innovation; 3D printing; Clothing industry.

\title{
1. Introdução.
}

Muitos dos produtos e serviços presentes em nosso cotidiano passaram a ocupar papéis de destaque e se tornaram até mesmo inevitáveis em nossas vidas. Para exemplificar, podemos refletir acerca do aperfeiçoamento de equipamentos de música, que se desenvolveram desde Walkmans até MP3, MP4 e, mais recentemente, os serviços disponibilizados em streaming como o iTunes e Spotify. Como tais concepções se tornaram realidade? Boas ideias não são automaticamente transformadas em funcionais. Para que isto aconteça, é necessário que o Processo de Desenvolvimento de Produto (PDP) seja administrado por meio de uma lista de atividades que garantam que o eventual produto seja produzível, acessível, confiável e atrativo aos consumidores. A execução de tais atividades ocorre durante o processo de desenvolvimento de produto quando sumarizadas de acordo com algum dentre os muitos modelos de referência de PDP (HART, 2016).

Conforme Santis et al. (2017) vários estudos foram realizados a fim de encontrar a melhor maneira de se criar um produto, as maneiras e os métodos diferem, mas, em geral, todos buscam contribuir para o desenvolvimento de produtos. Treptow (2013) acrescenta que dependendo do produto a ser fabricado, suas especificidades e acabamentos podem agregar ou reduzir etapas no processo de desenvolvimento do produto.

Salerno et al. (2015) defendem que os modelos tradicionais de desenvolvimento de produtos não aderem a tipos de projetos importantes, como aqueles com alto grau de incerteza e complexidade, que são típicos da inovação radical que envolve novos avanços tecnológicos e/ou novos mercados. Mas, de acordo com Snyder et al. (2016), níveis mais elevados de magnitude da inovação (ou seja, mais radicais em oposição ao incremental) apresentam um melhor desempenho na introdução de novos produtos.

Uma adição recente às práticas industriais consiste na impressão tridimensional (GEBLER; UITERKAMP; VISSER, 2014). Cautela, Pisano e Pironti (2014) indicam que a impressão 3D representa uma tecnologia de inovação radical. Rayna e Striukova (2016) expõem que usadas originalmente para prototipagem rápida, as tecnologias de impressão 3D assumiram progressivamente um papel importante nos processos de manufatura. Com o avanço dessa tecnologia, possibilitou-se usar as impressoras 3D não apenas para o protótipo, mas também para fabricar ferramentas e moldes utilizados na fabricação "tradicional" e, em alguns casos, tornou-se viável e econômico fabricar inteiramente produtos finais.

Por meio da impressão 3D é possível dar novas formas às roupas e ainda esta tecnologia pode oferecer serviços personalizados e com funções adicionais como, por exemplo, a medição das partes do corpo. Os primeiros sapatos de corrida individuais das impressoras 3D já estão sendo disponibilizados, e esta tendência vai continuar (FASTERMANN, 2016). Tapia (2016) relata que a impressão 3D se 
apresenta como uma ferramenta que permite explorar novas linguagens dentro de um mundo, como o da moda, que necessita ser fomentado constantemente pela novidade.

Neste sentido, este artigo objetiva realizar uma análise crítica sobre os modelos de referência já consolidados na literatura e propor um modelo de referência específico para o Processo de Desenvolvimento de Produtos de Vestuário para a Impressão 3D (PDPVI3D) para guiar o desenvolvimento dessas peças inovadoras. Como prova de conceito, foi desenvolvida a modelagem de um protótipo de sapato de salto alto feminino e sua impressão utilizando o filamento Acrilonitrila Butadieno Estireno (ABS).

Sendo assim, este artigo está estruturado da seguinte forma: além desta introdutória, a Seção 2 apresenta a revisão de literatura que o fundamentou, abrangendo a descrição do PDP com inclusão de modelos de referência (contendo adaptações de dois modelos de referência generalistas e de três específicos, inicialmente um Modelo de Referência Mecatrônico (MRM) e na sequência dois modelos voltados para o vestuário, as tecnologias de impressão 3D e softwares de desenho e também algumas aplicações 3D na indústria da moda; A Seção 3 denota o método de pesquisa utilizado; A Seção 4 apresenta a análise comparativa entre os modelos de referência selecionados; A Seção 5 relata os resultados e discussões obtidos tanto com a proposta de modelo de referência PDPVI3D criado, mas também com àqueles referentes a modelagem e impressão do sapato de salto alto; e as considerações finais são apresentadas na Seção 6.

\section{Fundamentação teórica.}

Nesta seção são abordados os conceitos relacionados ao processo de desenvolvimento de produtos, modelos de referência e tecnologias de impressão 3D.

\subsection{Processo de Desenvolvimento de Produtos.}

A primeira menção de um Processo de Desenvolvimento de Produto (PDP) na literatura ocorreu em 1966 e, ao longo dos anos 80 e 90, muitos pesquisadores investigaram processos formais de PDP determinando quais eram os aspectos mais altamente associados com o sucesso e o desenvolvimento efetivo de processos. Essencialmente, essa pesquisa ambicionou transformar a "arte" do desenvolvimento de produto em uma ciência (GRIFFIN et al., 2014).

O PDP é o modo como as atividades e tarefas concernentes ao projeto de desenvolvimento de produtos são desenvolvidas e gerenciadas. Ele parte da ideia inicial a respeito das necessidades do mercado e das possibilidades tecnológicas e considera as estratégicas corporativas, de negócios e de produto da organização, até chegar às especificações de projeto de um produto e de seu processo de fabricação (BORNIA; LORANDINI, 2008). Souza (2016) explica que o PDP é constituído de várias etapas que percorrem desde descobertas de novas necessidades do usuário, do desenvolvimento, avaliação, testes e finalmente do descarte do produto.

Conforme $\mathrm{Hu}$, Jun e Foley (2016), o processo de desenvolvimento de produtos é fundamental para estimular o crescimento econômico dos negócios. PDP's bem-sucedidos não apenas apoiam atividades comerciais importantes que contribuem para a rentabilidade das empresas em longo prazo, mas também fornecem a elas pontes de corte em batalhas competitivas. Paula e Mello (2012) mostram que a vantagem competitiva é um objetivo da sistematização processual de um produto realizada por uma empresa.

Ultimamente, o processo de desenvolvimento de produtos aumentou consideravelmente. Uma das maiores preocupações de grande parte do mercado é a busca pela inovação e desenvolvimento de novos produtos (TARICHI et al., 2016). Bouncken et al. (2017) veiculam a hipótese de que mesmo que se espere que a competitividade tenha efeitos positivos na fase de lançamento para os ambos tipos de 
inovação: incremental e radical, esses efeitos são mais fortes na inovação radical. A inovação radical está associada com a adoção de novas tecnologias. É um processo complexo, que demanda maior tempo, com um risco maior e tem impacto significativo nas atividades da empresa, gerando benefício aos clientes. A inovação radical, geralmente, gera mudanças no modelo de negócio e/ou tipo de mercado (SHIH, 2018).

Avraham (2016) destaca que, os inovadores que desenvolvem novos produtos precisam ter uma forte consciência dos ambientes globais e locais nos quais serão vendidos. Para Kuester, Decker e Schumacher (2016) a cooperação com os clientes no PDP é essencial, podendo influenciar positivamente o sucesso do produto no mercado e seu grau de inovação.

Auer (2016) afirma que o principal objetivo de uma empresa em integrar clientes no processo de agregação de valor é obter uma melhor visão do mercado e minimizar o risco de desenvolver produtos indesejáveis. Isso facilita a entrada de produtos no mercado e atrai novos clientes. Ao mesmo tempo, os clientes de referência melhoram a posição competitiva e a imagem da empresa frente às outras organizações.

\subsubsection{Modelos de referência.}

Modelos de referência são orientações para o desenvolvimento de novos produtos. Estas diretrizes funcionam como um passo a passo, iniciando com a concepção do produto até o seu lançamento no mercado. Alguns deles, englobam também a descontinuação do produto no mercado.

Os modelos de referência generalistas fornecem uma direção adaptativa para diversas condições e tipos de processos. Os modelos específicos, por sua vez, são considerados como particulares de um setor ou indústria e apresentam características singulares (BORSATO et al., 2016).

Normalmente, os modelos de referência são estruturados em fases, gates e atividades. As fases são o nível mais baixo de abstração em um modelo e são separadas pelos momentos de avaliação e tomada de decisão chamados gates. Finalmente, cada fase é representada de forma detalhada por suas atividades (MARQUES et al., 2016).

Os principais modelos identificados foram:

- Modelo de Back et al. (2008): de acordo com Back et al. (2008) os produtos são compostos por elementos que integram os seguintes atributos básicos: aparência, formato, coloração, função, imagem, material, embalagem, marca, serviços pós-venda e garantias. Para o desenvolvimento de um produto eficaz e eficiente deve-se saber como fazê-lo, com o que fazêlo, quando e para quem realizá-lo.

- Modelo de Baxter (2011): A atividade de desenvolvimento de um novo produto requer pesquisa, cauteloso planejamento, controle minucioso e, especialmente, o uso de métodos sistemáticos. Estes métodos de desenvolvimento de um novo produto envolvem técnicas de marketing, engenharia de métodos e emprego de conhecimentos de estética e estilo. Este conhecimento é suficiente para fornecer uma visão global sobre o PDP de novos produtos (BAXTER, 2011).

Os modelos de referência específicos para o vestuário identificados foram:

- Modelo mecatrônico de Barbalho e Rozenfeld (2013): Os autores Barbalho e Rozenfeld (2013) argumentam que a utilização de modelos de referência implica em uma melhoria no processo de desenvolvimento de produtos e apresentam um Modelo de Referência Mecatrônico (MRM) desenvolvido com base nas melhores práticas detectadas de desenvolvimento de produtos mecatrônicos pela academia. 
- Modelo de Moretti e Braghini (2017): As empresas que produzem peças de vestuário possuem algumas características específicas em seu processo de desenvolvimento de produtos como, por exemplo, a necessidade de várias coleções ao longo do ano. Estas características aumentam a complexidade do PDP neste setor. Portanto, a criação de um modelo de referência voltado para processo de desenvolvimento de produtos de vestuário (PDPV) e moldado as suas características é uma forma de melhorar o processo de desenvolvimento (MORETTI; BRAGHINI, 2017).

- Modelo de Lima et al. (2017): O modelo incentiva a introdução de práticas sustentáveis ao longo de todo o processo, guiando as empresas à conscientização nos níveis ambiental, social e econômico.

\subsection{Tecnologia de impressão 3D.}

A impressão 3D é uma técnica de manufatura aditiva que fabrica uma gama de geometrias e estruturas complexas, a partir de dados de modelos tridimensionais (3D) (NGO et al., 2018). Isso é possível devido ao seu processo aditivo, em que sucessivas camadas de material são definidas em diferentes formas, sendo esta distinta dos processos subtrativos (aqueles que apresentam as técnicas tradicionais de usinagem). Por meio do estabelecimento de sucessivas camadas transversais de um material correspondente ao modelo virtual CAD, estas são unidas ou fundidas obtendo-se a peça final (KUMAR, L.; KUMAR, V.; HALEEM, 2016).

As várias máquinas de impressão 3D permitem a impressão de diferentes maneiras, sendo as principais diferenças a forma como as camadas da impressão são acumuladas umas em cima das outras na medida em que liberarem o material de seu cartucho. Cada camada é efetivamente uma fatia digital concebida por meio de um determinado projeto auxiliado por computador (CAD). A adição dessas camadas ocorre até o objeto ser totalmente impresso ou fabricado podendo ser com uma extrusora (filamento fundido), agente químico (aglutinante) ou um laser (sinterização/derretimento) que altera o estado do material. Assim, conforme o material é estratificado, produz-se um objeto 3D (BIRTCHNELL; URRY, 2013).

As matérias-primas utilizadas pelas impressoras 3D são plásticos, resinas, superligas como o cromo à base de níquel e como a liga de cobalto-cromo, aço inox, titânio, polímeros e cerâmica. A impressão 3D pode ser utilizada na indústria para fazer protótipos, maquetes, peças de reposição, mockups, entre outros (BERMAN, 2012). Montes (2016) acrescenta que a impressão 3D permitiu a fabricação direta em casa e um desenvolvimento de produtos mais rápido e barato.

\subsubsection{Aplicações de impressão 3D na moda.}

Em relação ao uso da impressão 3D na moda, a designer de moda Danit Peleg ${ }^{\dagger}$ completou sua segunda coleção projetada e criada exclusivamente para impressoras 3D de uso doméstico. Para Corral e Walker (2017) os projetos desta designer refletem a possibilidade de que a roupa impressa em 3D possa suplantar roupas de tecido tradicionais e ser criada com muito pouco ou nenhum desperdício. Os autores destacam que a impressão 3D pode ser utilizada para a criação de peças do vestuário e que, em geral, os consumidores estão interessados em seu potencial e gostariam de ver uma maior aplicação desta tecnologia no ramo da moda.

Andrade (2013) salienta que podem ser atribuídos aos calçados conceitos, referências e tendências de moda utilizando o design e inovações como, por exemplo, novas combinações e uso de diferentes materiais. A impressão em 3D de um calçado exige propriedades estruturais específicas. O sapato flames

†http://danitpeleg.com/photos/ 
uniu a linguagem arquitetônica de Hadid e a experiência da United Nude, resultando um dos projetos mais inovadores incorporados a um sapato (UNITED NUDES, 2015). Julian Hakes projetou um sapato que denominou de The Mojito em meio a um pensamento que o design dos sapatos tinha estagnado em sua própria tradição com as mesmas repetições ao invés de inovações (GRAIN; UNVER, 2016).

Corral e Walker (2017) evidenciam que a impressão 3D pode ser utilizada para a criação de peças do vestuário e que, em geral, os consumidores estão interessados em seu potencial e gostariam de ver uma maior aplicação desta tecnologia no ramo da moda.

Vanderploeg, Lee e Mamp (2017) destacam que a tecnologia 3D oferece uma alternativa inovadora à indústria da moda, no que se refere ao design e processo de fabricação. Os autores analisaram cinco métodos de impressão 3D em relação ao tamanho da impressão, materiais, benefícios, desafios e categorias de produtos potenciais (sapatos, acessórios e vestidos) e destacam que o tamanho do produto e materiais desejados sãos os fatores que mais influenciam na escolha do método de impressão.

Perry (2017) conduziu um estudo para analisar as percepções do consumidor sobre roupas produzidas a partir da impressão 3D. O estudo analisou três dimensões: i) vantagens, ii) preocupações e iii) compras. Os resultados destacam que as desvantagens da impressão 3D são o conforto, facilidade de movimento, custo, durabilidade e cuidado.

Spahiu, Canaj e Shehi (2020) testaram várias geometrias e materiais (rígidos e flexíveis) e criaram um vestido utilizando a impressão 3D. A peça foi avaliada e a maioria dos participantes se mostrou favorável ao uso. Os autores destacam que além da impressão de tecidos em 3D, há uma oportunidade de combinar o tecido têxtil com geometrias impressas.

\section{Método de pesquisa.}

Do ponto de vista de sua natureza, este artigo se classifica como pesquisa aplicada, dado que o conhecimento gerado objetivou a aplicação prática destinada à solução de problemas específicos. No que se refere a sua abordagem, trata-se de uma pesquisa qualitativa, uma vez que as informações reunidas para sua elaboração não se utilizaram de técnicas estatísticas e foram observadas de forma subjetiva. Com respeito ao enfoque objetivo, a pesquisa se caracteriza como exploratória, visto que proporciona maior familiaridade com o tema proposto por meio da análise de textos e exemplos intencionando a sua compreensão. Somado a isso, a pesquisa ainda é definida pela ótica dos procedimentos técnicos como bibliográfica e também como um estudo de caso, em razão de sua elaboração por meio de embasamentos científicos e ser voltada ao desenvolvimento de um modelo de referência que exigiu profundo e minucioso estudo, respectivamente (PRODANOV; FREITAS, 2013).

Foi realizada uma busca nas bases de dados utilizando os termos: Processo de Desenvolvimento de Produtos; Processo de Desenvolvimento de Produtos de Vestuário; Modelo de Referência Generalistas; Modelos de Referência Específicos; Tecnologia de Impressão 3D; entre outros termos relacionados a estes nos idiomas português e inglês. Os modelos de referência foram selecionados por relevância e atualidade (período de sua data de publicação não inferior a 10 anos). Outro fator que influenciou a escolha dos modelos de referências foi eleger modelos generalistas "clássicos" que satisfizeram os critérios anteriores. Por este motivo, o modelo de Barbalho e Rozenfeld (2013), mesmo sendo um modelo mecatrônico foi selecionado. Uma vez que escolhidos, os modelos foram estudados e então adaptados em uma forma única para melhor visualização de suas fases, atividades e gates.

A partir desses elementos foi realizada a proposta para o modelo de referência com base na comparação dos modelos previamente selecionados, tanto generalistas quanto específicos, pelo fato de os generalistas serem modelos tradicionais e os específicos agregarem conhecimento para a área de atuação. Os critérios nesta comparação foram manter os pontos onde houve a equivalência de fases e atividades entre pelo menos dois modelos, acrescentar os pontos em que os autores independentemente 
identificaram melhorias e excluir os pontos obsoletos para a tecnologia de impressão 3D. Além disso, baseado na pesquisa realizada sobre a impressão 3D e no desenvolvimento da modelagem e impressão do protótipo (que foram realizadas simultaneamente com a elaboração do modelo), foi possível adicionar aspectos necessários para esta tecnologia específica.

Para a prova de conceito foi utilizado o software de desenho Blender e a impressora 3D da marca UP3D no modelo UP Plus 2, com o material Acrilonitrila Butadieno Estireno (ABS), por ser o filamento disponível no centro de pesquisa, no entanto é importante ressaltar que a cor do filamento, sendo esses ABS, PLA, PETG etc, interferem na temperatura de extrusão. Spahiu, Canaj e Shehi (2020) destacam que materiais reciclados como náilon, TPU (poliuretano termoplástico) ou PLA (ácido polilático) têm chamado a atenção de designers de moda para desenvolver produto têxtil impressos em 3D, neste caso auxiliando na redução de resíduos por consumo (encaixe de peças no tecido) e por reciclagem de material (SPAHIU, CANAJ e SHEHI, 2020).

A escolha de se desenvolver um sapato deu-se por este item do vestuário apresentar mais aplicações na indústria da moda (KIM et al., 2016; AMZA; ZAPCIU; POPESCU, 2019; PARK e LEE, 2019; SPAHIU et al., 2020; KOSTYLEVA e KONOVALOVO, 2020).

\section{Resultados.}

Neste seção é apresentada a proposta de modelo de referência para o PDPV voltado para a impressão tridimensional e a prova de conceito com a modelagem e impressão do sapato de salto alto.

\subsection{Análise comparativa dos modelos de referência.}

Nesta seção é apresentada uma análise comparativa detalhada entre as atividades de cada fase desses modelos. Os modelos de referência foram selecionados por relevância e atualidade (período de sua data de publicação não inferior a 10 anos). Outro fator que influenciou a escolha dos modelos de referências foi eleger modelos generalistas "clássicos" que satisfizeram os critérios anteriores. Por este motivo, o modelo de Barbalho e Rozenfeld (2013), mesmo sendo um modelo mecatrônico foi selecionado. Uma vez que escolhidos, os modelos foram estudados e então adaptados em uma forma única para melhor visualização de suas fases, atividades e gates.

\subsubsection{Fases e atividades.}

As fases e atividades de todas as adaptações dos modelos para o PDP apresentados de Back et al. (2008), Baxter (2011), Barbalho e Rozenfeld (2013), Moretti e Braghini (2017) e Lima et al. (2017) foram dispostas conjuntamente, para facilitar a visualização de uma comparação entre eles, conforme ilustra o Quadro 1.

A partir de uma análise comparativa entre as atividades presentes nos distintos modelos de referência percebe-se que há algumas que são equivalentes entre os diferentes modelos apresentados e outras que são exclusivas de cada um. Além disso, a maneira com que cada autor organizou as atividades de seus modelos entre as fases possui particularidades.

\subsubsection{Pré-desenvolvimento.}

O Quadro 2 destaca as particularidades de cada atividade apresentada no pré-desenvolvimento dos modelos de referência abordados. 
Observa-se que no pré-desenvolvimento, os autores Back et al. (2008), Baxter (2011) e Barbalho e Rozenfeld (2013) iniciaram seus modelos levando em consideração a estratégia da organização e decisões que a envolve. Baxter (2011) dá um grande enfoque à decisão sobre a inovação dentro da definição de estratégia.

Back et al. (2008) estabeleceu nesta etapa a aprovação de um plano de marketing, seguido da definição dos envolvidos. Após uma declaração de escopo e a estrutura de decomposição do projeto, direciona para a avaliação dos riscos. A definição da equipe de gerenciamento do projeto somado das atividades de criação do plano do projeto é realizada.

Moretti e Braghini (2017) também definem a escolha do time, somada do sequenciamento das atividades, do planejamento de datas e da elaboração de indicadores de performance. Estipulam ainda uma revisão sobre as vendas de coleções passadas, uma análise do cenário e público-alvo, definição do setor de trabalho e análise da viabilidade econômica. 
Quadro 1 - Fases e atividades dos modelos de referência apresentados simultaneamente

\begin{tabular}{|c|c|c|c|c|c|}
\hline & $\underset{(2008)}{\text { BACK ET } A L .}$ & BAXTER (2011) & $\begin{array}{c}\text { BARBALHO E } \\
\text { ROZENFELD } \\
(\mathbf{2 0 1 3})\end{array}$ & $\begin{array}{c}\text { MORETTI E } \\
\text { BRAGHINI } \\
(\mathbf{2 0 1 7 )} \\
\end{array}$ & 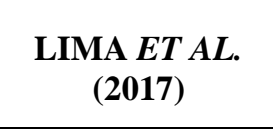 \\
\hline 产 & $\begin{array}{l}\text { - Planejamento } \\
\text { do Projeto. }\end{array}$ & $\begin{array}{l}\text { - Decisões sobre } \\
\text { Estratégia; } \\
\text { - Oportunidades } \\
\text { de Inovação. }\end{array}$ & $\begin{array}{l}\text { - Planejamento do } \\
\text { Produto. }\end{array}$ & $\begin{array}{l}\text { - Planejamento } \\
\text { da Coleção; } \\
\text { - Planejamento } \\
\text { do Portfólio de } \\
\text { Produtos. }\end{array}$ & $X$ \\
\hline$\sum_{\substack{0 \\
0}}^{0}$ & $\begin{array}{l}\text { - Projeto } \\
\text { Informacional; } \\
\text { - Projeto } \\
\text { Conceitual; } \\
\text { - Projeto } \\
\text { Preliminar; } \\
\text { - Projeto } \\
\text { Detalhado; } \\
\text { - Preparação da } \\
\text { Produção. }\end{array}$ & $\begin{array}{l}\text { - A Oportunidade } \\
\text { Específica para o } \\
\text { Desenvolvimento } \\
\text { do Novo Produto; } \\
\text { - Projeto } \\
\text { Conceitual; } \\
\text { - Projeto de } \\
\text { Configuração; } \\
\text { - Projeto } \\
\text { Detalhado; } \\
\text { - Fabricação. }\end{array}$ & $\begin{array}{l}\text { - Portfólio; } \\
\text { - Especificações; } \\
\text { - Planejamento do } \\
\text { Projeto; } \\
\text { - Concepção; } \\
\text { - Planejamento } \\
\text { Técnico; } \\
\text { - Otimização. }\end{array}$ & $\begin{array}{l}\text { - Pesquisa de } \\
\text { Tendências do } \\
\text { Mercado; } \\
\text { - Definição do } \\
\text { Conceito; } \\
\text { - } \\
\text { Detalhamento; } \\
\text { - Pré- } \\
\text { produção; } \\
\text { - Lançamento } \\
\text { da Coleção. }\end{array}$ & $\begin{array}{l}\text { - Planejamento } \\
\text { do Produto; } \\
\text { - Coleta de } \\
\text { Informações: } \\
\text { Comportamentos, } \\
\text { Materiais e } \\
\text { Processos; } \\
\text { - Geração e } \\
\text { Seleção de } \\
\text { Moldes; } \\
\text { - Modelagem } \\
\text { Eficiente e Peça } \\
\text { Piloto Conforme } \\
\text { a Necessidade. }\end{array}$ \\
\hline 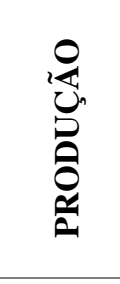 & $X$ & $X$ & $\begin{array}{l}\text { - Homologação; } \\
\text { - Validação. }\end{array}$ & $X$ & $\begin{array}{l}\text { - Produção com } \\
\text { as Etapas de } \\
\text { Ficha Técnica e } \\
\text { Detalhamento de } \\
\text { Materiais Usados; } \\
\text { - Produção Ética } \\
\text { e Expedição. }\end{array}$ \\
\hline 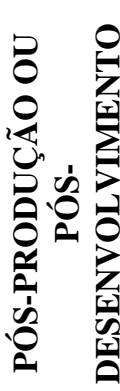 & $\begin{array}{l}\text { - Lançamento } \\
\text { do Produto; } \\
\text { - Validação do } \\
\text { Produto. }\end{array}$ & $X$ & $\begin{array}{l}\text { - Lançamento; } \\
\text { - Monitoramento. }\end{array}$ & $\begin{array}{l}\text { - Monitorar o } \\
\text { Processo. }\end{array}$ & $\begin{array}{l}\text { - Lançamento/ } \\
\text { Comunicação do } \\
\text { Produto; } \\
\text { - Distribuição } \\
\text { com Redução de } \\
\text { Transporte; } \\
\text { - Venda Justa; } \\
\text { - Gestão de Fim } \\
\text { de Ciclo de Vida. }\end{array}$ \\
\hline
\end{tabular}

Fonte: adaptado de Back et al. (2008); Baxter (2011); Barbalho e Rozenfeld (2013); Moretti e Braghini (2017); e Lima et al. (2017) 


\subsubsection{Desenvolvimento.}

O Quadro 3 apresenta uma comparação da fase de desenvolvimento entre os modelos de referência selecionados.

Barbalho e Rozenfeld (2013) indicam no desenvolvimento a definição do portfólio de cada LDP. Back et al. (2008) inicia o desenvolvimento de seu modelo com a identificação das necessidades dos clientes, seguidos da definição dos requisitos do projeto do produto levando em conta atributos como funcionalidade, modularidade, estética, legislação, entre outros. Na sequência, são definidas: influência no plano da fabricação, estratégia para relacionamento com fornecedores, ciclo de vida e metas de dependabilidade e de custo.

Quadro 2 - Comparações entre atividades no pré-desenvolvimento

\section{BACK ET AL. $\quad$ BAXTER (2011) (2008)}

- Planejamento do
Projeto:
Etapa de
planejamento de
um projeto novo
levando em
consideração as
estratégias da
empresa.

$\begin{array}{ll}\text { - Decisões sobre } & \text { - Planejamento } \\ \text { Estratégia: } & \text { do Produto: } \\ \text { As organizações } & \text { Deve-se definir } \\ \text { devem tomar a } & \text { a estratégia a } \\ \text { decisão se querem ou } & \text { ser seguida em } \\ \text { não inovar, mas esta } & \text { cada linha de } \\ \text { decisão é complexa e } & \text { produtos } \\ \text { apresenta um grande } & \text { (LDP). } \\ \text { grau de incerteza } & \end{array}$
grau de incerteza.

\section{- Oportunidades de Inovação:}

No caso da empresa optar pela inovação e o plano estratégico da organização receber essa medida, o próximo passo é examinar todas as oportunidades de inovação possíveis objetivando selecionar a melhor delas.

\section{BARBALHO MORETTI E E BRAGHINI} ROZENFELD (2017)

LIMA $E$ T

AL. (2017)

(2013)

$\begin{array}{ll}\text { - Planejamento } & \text { - Planejamento } \\ \text { do Produto: } & \text { da Coleção: } \\ \text { Deve-se definir } & \text { Identificam-se } \\ \text { a estratégia a } & \text { as partes } \\ \text { ser seguida em } & \text { envolvidas na } \\ \text { cada linha de } & \text { coleção e as } \\ \text { produtos } & \text { necessidades e } \\ \text { (LDP). } & \text { controles para o } \\ & \text { processo são } \\ & \text { analisados. }\end{array}$

- Planejamento
do Portfólio de
Produtos:
Define-se a
grade de
vestuário que
será
desenvolvida na
coleção.

Fonte: adaptado de Back et al. (2008); Baxter (2011); Barbalho e Rozenfeld (2013); Moretti e Braghini (2017); e Lima et al. (2017)

As duas atividades iniciais apresentadas por Back et al. (2008) e Baxter (2011) são equivalentes entre si. Dentre os passos de planejamento do produto apresentados por Baxter (2011) ainda não citadas pelos demais autores, é possível notar a pesquisa e análise das oportunidades e restrições e a especificação do novo produto e sua justificativa.

Após estas definições, em ambos os modelos, de Back et al. (2008) e de Baxter (2011), o projeto conceitual é estabelecido. Back et al. (2008) explica que o projeto conceitual consiste em mostrar a maneira que o novo produto será realizado para atender aos objetivos básicos. Deste modo, o maior número possível de conceitos deve ser gerado para se selecionar o melhor dentre eles. Feito isto, Baxter (2011) indica que se deve fazer uma análise alternativa considerando as especificações do projeto, o custo meta, os riscos decorrentes do desenvolvimento, as metas de qualidade, de dependabilidade e de segurança. Com isso, se define qual processo de fabricação será utilizado. 
No modelo de Barbalho e Rozenfeld (2013) o projeto conceitual é dividido entre três fases, sendo elas: especificações, planejamento de projeto e concepção. Na fase de especificação a particularização de cada produto é realizada, no planejamento do projeto se cria o plano de projeto para cada produto e na fase de concepção, os principais componentes e soluções para funções do produto são estabelecidos.

Na sequência do modelo de Back (2008), o layout final do produto e sua viabilidade técnica e econômica são realizados em um projeto preliminar. Quando finalizado, realiza-se o plano de fabricação e teste do protótipo e a realização da estrutura preliminar do protótipo. Realiza-se então a análise da capacidade da manufatura dos componentes internamente e externamente. Posteriormente, uma viabilidade econômica é realizada dentro do plano estratégico.

Quadro 3 - Comparações entre as atividades no desenvolvimento

BACK ET AL. BAXTER (2011) BARBALHO E MORETTI E (2008)

\section{ROZENFELD}

(2013)

- Projeto Conceitual:

Desenvolvimento da concepção do produto.

A estrutura funcional

do item a ser

produzido é

estabelecida.

\section{- Projeto Preliminar:}

Esta fase visa a realização do layout final do produto e o desígnio de sua visibilidade técnica e econômica.

- Projeto Detalhado:

Há a aprovação do protótipo, término das especificações dos componentes, detalhamento do plano de manufatura e preparo do pedido de investimento.

- Preparação da
Produção:
O produto é lançado no
mercado.

- Oportunidade

Específica para o

Desenvolvimento

do Novo Produto:

Ocorre o

planejamento do

- Portfólio:

Define-se o

portfólio de

cada LDP.

produto.

\section{- Projeto}

Conceitual:

Construção de parâmetros de projeto para o novo produto.

- Projeto de Configuração:

A configuração do projeto atua sobre o conceito selecionado e determina como ele será executado.

- Projeto

Detalhado:

Composto de desenhos técnicos e especificações de fabricação, suficientes para sua produção na fábrica.

- Fabricação
-

Especificações:

Estipula-se as especificações de cada produto.

- Planejamento do Projeto: Cria-se o plano de projeto do produto.

- Concepção:

Define-se os principais funções essenciais do produto.

\section{- Planejamento} Técnico: Detalhamento do plano do projeto conforme as definições.

- Otimização:

Estipula-se soluções técnicas para a utilidade do produto. componentes e
LIMA ET $A L$. (2017)

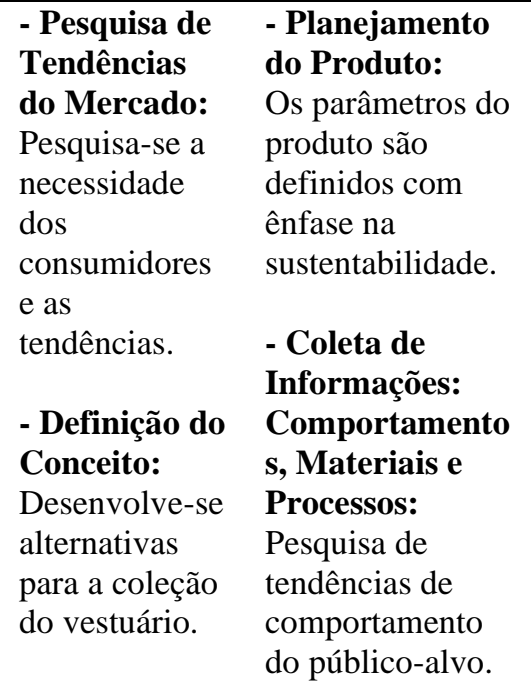

Detalhamento - Geração e Especifica-se o produto e se desenvolve a peça piloto.

- Préprodução: Detalham-se os processos de fabricação.

- Lançamento da Coleção: Planejamento de processos de vendas, distribuição e marketing.
Seleção de

Moldes:

$\mathrm{O}$ designer faz opções duráveis e modulares, focando o bemestar e a funcionalidade.

- Modelagem Eficiente e Peça Piloto Conforme a Necessidade: Uso eficiente de matéria prima, zero waste e tamanho único por modelistas competentes.

Fonte: adaptado de Back et al. (2008); Baxter (2011); Barbalho e Rozenfeld (2013); Moretti e Braghini (2017); e Lima et al. (2017) 
O projeto de configuração apresentado por Baxter (2011) é equivalente a este projeto preliminar apresentado por Back (2008) e o projeto detalhado dos modelos de Back (2008) e Baxter (2011) também são equivalentes entre si e a fase de planejamento técnico no modelo do Barbalho e Rozenfeld (2013).

Back (2008) esclarece que o projeto detalhado compõe uma série de desenhos técnicos e tipificação da fabricação para a produção fabril. Nesta fase ocorre a especificação completa do produto, a divisão em etapas de sua fabricação e sua programação atribuindo prazos para cada finalização com a definição de um responsável qualificado. Baxter (2011) indica que outros intuitos desta fase são a aprovação do protótipo e a realização de uma solicitação de investimento concernente com a estratégia da empresa.

$\mathrm{Na}$ última fase do desenvolvimento do modelo de Back (2008) denominada preparação da produção ocorre o lançamento do produto no mercado, sendo a segunda fase de implementação do lote piloto, fabrica-se o lote inicial. Com a quantidade de vendas conferidas, é revisada uma certificação dos componentes de produção, realização de um cronograma de fabricação, programação do lote inicial. Com a venda do lote inicial é feito um monitoramento pelo pós-venda.

Barbalho e Rozenfeld (2013) têm como última etapa do desenvolvimento a fase de otimização que estabelece soluções técnicas para a utilidade do produto principal. O modelo de Baxter (2011) tem sua macrofase de desenvolvimento finalizada com a fabricação e esta atividade também representa o fim de seu modelo de referência.

Especialmente nesta fase, nota-se uma maior distinção entre os modelos generalistas dos específicos. A fase inicial do modelo de Moretti e Braghini (2017) denomina-se pesquisa de tendências do mercado. Nesta fase as necessidades dos consumidores e as tendências de moda são identificadas. Então se efetua uma geração de ideias que são selecionadas e ocorre a especificação de estilos para a coleção. Feito isto, escolhe-se um tema para a coleção. Este tema é avaliado e suas definições escritas em um documento.

Na próxima atividade do modelo de Moretti e Braghini (2017), ocorre a criação dos esboços dos modelos e a seleção de matéria prima. Então, associam-se as tendências identificadas com os modelos, monitora-se a viabilidade econômica de cada produto e realiza-se um documento com as decisões tomadas.

Na etapa de detalhamento do modelo de Moretti e Braguini (2017) ocorre uma especificação do produto e se desenvolve a peça piloto. Então a matéria prima é submetida a testes de qualidade, é realizado um desenho técnico, desenvolvimento de modelagem do vestuário, submete-se o vestuário para testes de corte, usabilidade e ergonomia. Após isto, desenvolve-se a sequência operacional das peças e o registro técnico das peças aprovadas. A embalagem é desenvolvida, há um monitoramento da viabilidade econômica de cada produto, avaliação da peça piloto e modelagem das medidas do vestuário.

Na sequência do modelo de Moretti e Braghini (2017), a fase de pré-produção estipula que os processos de fabricação que atendam às necessidades da coleção sejam detalhados. Define-se a aquisição de matéria-prima, a produção de mostruário, o preço inicial do produto, a obtenção de recursos financeiros de fabricação, o desenvolvimento e a otimização dos processos de fabricação, realização de treinamento, liberação da produção e efetuação de um documento com as seguintes definições.

No fim desta fase, Moretti e Braghini (2017) propõem o lançamento de produtos no mercado, com planejamento de processos de vendas e campanhas de marketing. Então, se realizam o planejamento de marketing e lançamento, o desenvolvimento de processos de venda, a avaliação do marketing da coleção, a promoção de marketing de lançamento, lançamento da coleção, gerenciamento do lançamento e elaboração de um documento contendo as decisões estabelecidas.

No modelo de Lima et al. (2017) há grande ênfase ao conceito de sustentabilidade. No planejamento do produto, devem-se constar decisões sobre qual foco terá a seleção de materiais (reaproveitamento ou renovabilidade) terá e no fim do ciclo de vida deve haver a prioridade sobre esse aspecto ecológico. Na próxima fase do modelo, há a pesquisa de tendências e comportamentos do público-alvo, um levantamento dos materiais e processos necessários na produção do produto que sejam viáveis tecnicamente e economicamente além de menos agressivos ao meio ambiente.

Subsequentemente, Lima et al. (2017) orientam o designer a desenvolver opções de produtos duráveis e modulares, com foco no bem-estar do usuário e a funcionalidade. Deve-se ainda mensurar a quantidade de material utilizada e a geração de resíduos. Finalmente, na fase de modelagem eficiente e 
peça piloto conforme a necessidade espera-se que o modelista tenha competência técnica para realizar a melhor modelagem selecionada.

Vale ainda ressaltar que as duas últimas atividades da fase desenvolvimento e a primeira atividade da fase de produção do modelo de Lima et al. (2017) correspondem à etapa de detalhamento do modelo proposto por Moretti e Braghini (2017), as quais correspondem às equivalências já apontados das atividades de planejamento técnico do modelo de Barbalho e Rozenfeld (2013) à etapa denominada de projeto detalhado dos modelos de Back et al. (2008) e Baxter (2011). Portanto, as realizações desta atividade são encontradas em todos os modelos de referência selecionados.

\subsubsection{Produção.}

O Quadro 4 apresenta a comparação na fase de produção entre as adaptações dos modelos de referência retratados.

Quadro 4 - Comparações entre fases e atividades na produção

\begin{tabular}{|c|c|c|c|c|c|}
\hline & $\begin{array}{c}\text { BACK } E T \\
A L . \\
(2008)\end{array}$ & $\begin{array}{c}\text { BAXTER } \\
\text { (2011) }\end{array}$ & $\begin{array}{c}\text { BARBALHO E } \\
\text { ROZENFELD } \\
(2013)\end{array}$ & $\begin{array}{c}\text { MORETTI E } \\
\text { BRAGHINI } \\
(2017)\end{array}$ & LIMA ET AL. (2017) \\
\hline 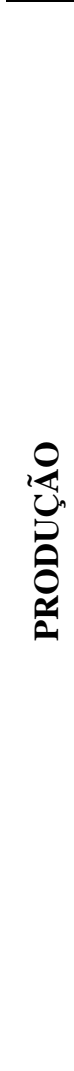 & $X$ & $X$ & $\begin{array}{l}\text { - Homologação: } \\
\text { Há o detalhamento } \\
\text { e testes para } \\
\text { soluções } \\
\text { secundárias e } \\
\text { realiza-se análises } \\
\text { ao aumento da } \\
\text { robustez e } \\
\text { confiabilidade do } \\
\text { produto. } \\
\text { - Validação: } \\
\text { Legitima-se o } \\
\text { processo de } \\
\text { fabricação e } \\
\text { montagem do } \\
\text { produto. }\end{array}$ & $X$ & $\begin{array}{l}\text { - Produção com as Etapas de } \\
\text { Ficha Técnica e Detalhamento } \\
\text { de Materiais Usados: } \\
\text { Confecciona-se uma ficha } \\
\text { técnica que contenha o desenho } \\
\text { planificado com medidas em } \\
\text { centímetros de frente, costas e } \\
\text { laterais do artigo de vestuário, } \\
\text { especificação dos materiais a } \\
\text { serem utilizados na peça } \\
\text { contendo nomes, conteúdos } \\
\text { sobre fornecedores, quantidades } \\
\text { necessárias e resíduos gerados. } \\
\text { - Produção Ética e Expedição: } \\
\text { Nesta fase a qualidade do } \\
\text { ambiente em que os } \\
\text { trabalhadores se encontram } \\
\text { como segurança, salários justos } \\
\text { e pausas para alimentação } \\
\text { apresenta relevância. Além } \\
\text { disso, deve-se apresentar um } \\
\text { foco em um estoque apropriado } \\
\text { sem remanescentes. } \\
\text { O estágio da expedição deve } \\
\text { funcionar também como um } \\
\text { controle de qualidade. }\end{array}$ \\
\hline
\end{tabular}

Fonte: adaptado de Back et al. (2008); Baxter (2011); Barbalho e Rozenfeld (2013); Moretti e Braghini (2017); e Lima et al. (2017)

Nesta fase, Barbalho e Rozenfeld (2013) estipulam a homologação: há o detalhamento e testes para a realização de resoluções secundárias além de análises ao aumento da robustez e confiabilidade do produto. Outra atividade proposta é a de validação, isto é, em que se legitima o processo de fabricação e montagem do produto.

Lima et al. (2017) indicam a fase de produção com as etapas de ficha técnica e detalhamento de materiais usados, onde deve-se confeccionar uma ficha técnica que contenha o desenho planificado com as medidas do vestuário, especificações, materiais, conteúdos sobre fornecedores, quantidades 
necessárias e resíduos gerados. A fase seguinte denomina-se produção ética e expedição. Nela, a qualidade do meio ambiente em que os trabalhadores se encontram, salários justos e pausas para alimentação são importantes.

\subsubsection{Pós-produção ou pós-desenvolvimento.}

O Quadro 5 apresenta a comparação da fase de pós-produção ou pós-desenvolvimento entre os modelos de referência selecionados.

Para Back (2008) antes do lançamento do produto é realizado o plano de marketing, a literatura técnica para divulgação e definidas as promoções do produto. As datas também são determinadas e a quantidade de vendas conferidas. A seguir, é revisada uma certificação dos componentes de produção em série e realização de um cronograma de manufatura dos itens do lote inicial. Depois da aprovação, o produto é lançado no mercado com uma apresentação aos consumidores.

O monitoramento é realizado pelo pós-venda e a validação do produto é realizada pela avaliação dos usuários e à auditoria junto ao cliente. Um relatório é montado e a partir da análise desse relatório definidas as operações para melhoria.

Barbalho e Rozenfeld (2013) destacam que o monitoramento do produto é realizado por meio da observação dos resultados por ele obtidos. Na sequência, é realizado um gerenciamento das alterações feitas na configuração inicial do produto.

Moretti e Braghini (2017) defendem que para o monitoramento do pós-lançamento é preciso realizar uma avaliação da satisfação dos clientes, acompanhar o desempenho do produto e proporcionar auxílio com práticas de eliminação dos produtos

Lima et al. (2017) enfatizam a necessidade de uma forte comunicação antes do lançamento do produto para sua aceitação pelo público alvo. Ainda ressalta que as características produtos de moda sustentável devem ser evidenciadas, pois representam um diferencial. Sugerem também que a empresa colete os produtos e elabore um sistema de reciclagem. 
Quadro 5 - Comparações entre fases e atividades na pós-produção ou pós-desenvolvimento

BACK $E T A L$. BAXTER BARBALHO E MORETTI E

(2008)

(2011) (2013) (2017)

\begin{tabular}{|c|c|c|c|c|c|}
\hline & & & & & \\
\hline 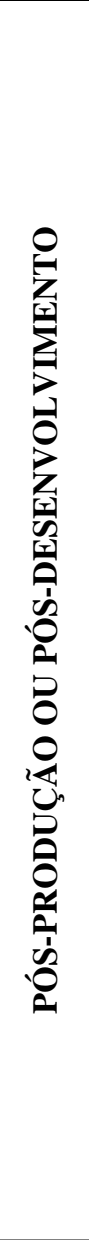 & $\begin{array}{l}\text { - Lançamento do } \\
\text { Produto: } \\
\text { O produto é lançado } \\
\text { no mercado. } \\
\text { Constituindo na } \\
\text { segunda fase de } \\
\text { implementação do } \\
\text { lote piloto, é feita a } \\
\text { fabricação do lote } \\
\text { inicial. } \\
\text { - Validaçãa do } \\
\text { Produto: } \\
\text { Validação do } \\
\text { produto junto aos } \\
\text { usuários e à } \\
\text { auditoria junto ao } \\
\text { cliente. Aqui o } \\
\text { projeto é encerrado. }\end{array}$ & $X$ & $\begin{array}{l}\text { - Lançamento: } \\
\text { O produto é } \\
\text { lançado no } \\
\text { mercado. } \\
\text { - Monitoramento: } \\
\text { Por fim, há o } \\
\text { acompanhamento } \\
\text { dos resultados } \\
\text { alcançados com o } \\
\text { produto e então é } \\
\text { feito um } \\
\text { gerenciamento das } \\
\text { alterações } \\
\text { realizadas na } \\
\text { configuração inicial } \\
\text { do produto. }\end{array}$ & $\begin{array}{l}\text { - Monitorar o } \\
\text { Processo: } \\
\text { Nesta última } \\
\text { fase se } \\
\text { monitora, } \\
\text { documenta e } \\
\text { trata das } \\
\text { informações a } \\
\text { respeito do } \\
\text { pós- } \\
\text { lançamento. }\end{array}$ & $\begin{array}{l}\text { - Lançamento/ } \\
\text { Comunicação do Produto: } \\
\text { Sugere-se que a entrada do } \\
\text { produto no mercado seja } \\
\text { antecedida de uma forte } \\
\text { comunicação e lançamento } \\
\text { para o produto, sendo } \\
\text { responsável pela futura } \\
\text { aceitação do produto pelo } \\
\text { seu público-alvo. } \\
\text { - Distribuição com } \\
\text { Redução de Transporte: } \\
\text { Recomenda-se que } \\
\text { alternativas para a } \\
\text { distribuição logística do } \\
\text { produto sejam pensadas. } \\
\text { - Venda Justa: } \\
\text { Aconselha-se que seja } \\
\text { definido um preço justo pelo } \\
\text { produto. } \\
\text { - Gestão de Fim de Ciclo } \\
\text { de Vida: } \\
\text { Propõe-se às organizações } \\
\text { que um sistema de conserto } \\
\text { seja incorporado em seus } \\
\text { processos produtivos para } \\
\text { futuras necessidades dos } \\
\text { clientes. }\end{array}$ \\
\hline
\end{tabular}

Fonte: adaptado de Back et al. (2008); Baxter (2011); Barbalho e Rozenfeld (2013); Moretti e Braghini (2017); e Lima et al. (2017)

4.2 Proposta de modelo de referência para o processo de desenvolvimento de produto de vestuário impresso tridimensionalmente (PDPVI3D).

A partir dos modelos analisados e dos critérios propostos quanto à equivalência de fases e atividades entre pelo menos dois modelos, adição de pontos em que os autores independentemente identificaram melhorias, exclusão de pontos obsoletos para a tecnologia de impressão 3D e acréscimo de pontos intrínsecos a esta tecnologia identificados foi proposto um modelo de referência PDPVI3D (Figura 1). 


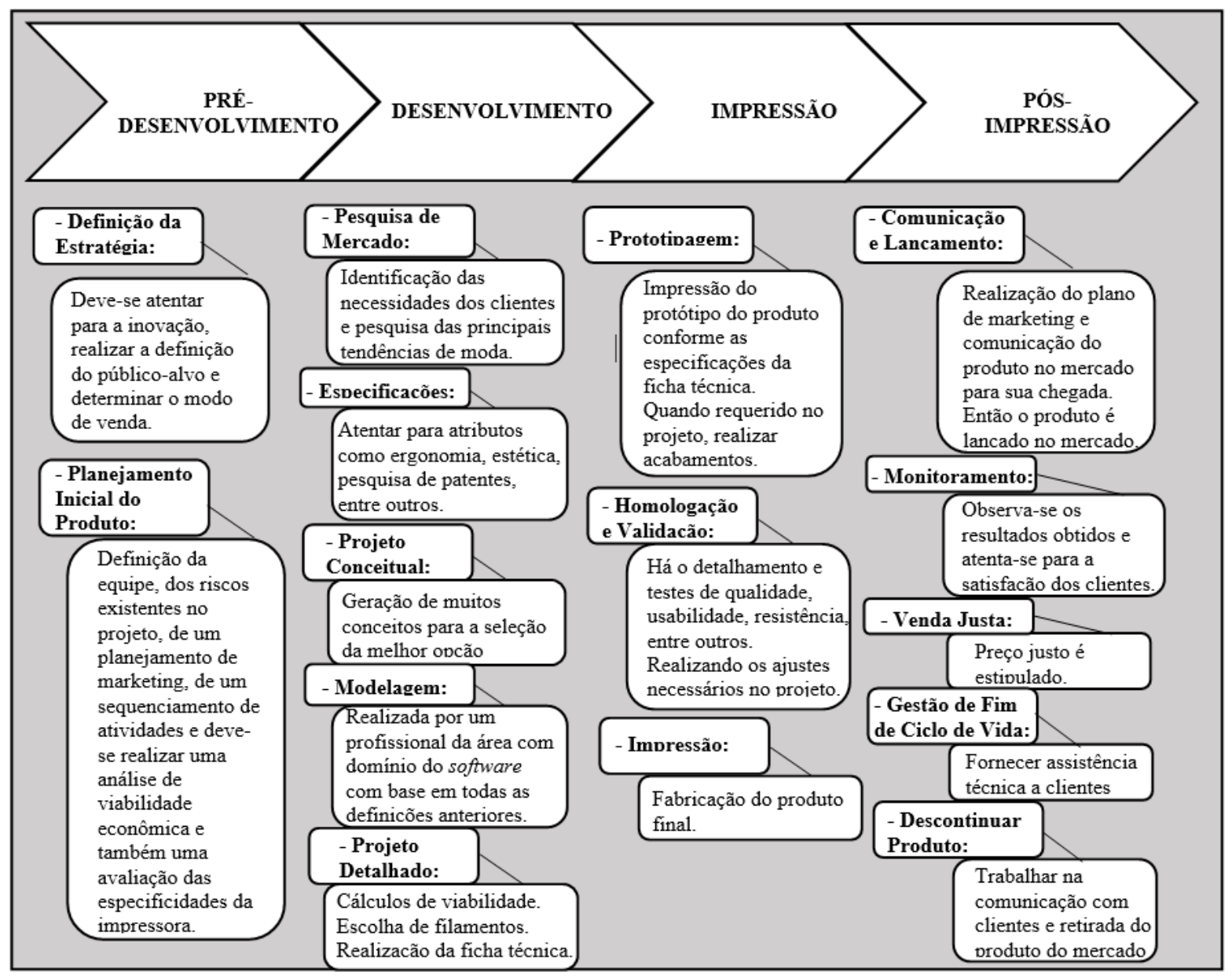

Figura 1 - Proposta de Modelo de PDPVI3D

Fonte: autoria própria (2017)

As atividades identificadas como necessárias na impressão 3D do protótipo para o prédesenvolvimento foram duas. A primeira é a definição da forma de venda do projeto, isto é, se deverá ser vendido já impresso ou se a venda será realizada por meio de download da modelagem do produto. $\mathrm{O}$ outro fator consiste em realizar uma avaliação das especificidades da impressora (tamanho de impressão disponível, número de cores de filamento que podem ser impressas em conjunto, entre outros).

Para o desenvolvimento, notou-se na impressão do protótipo que a impressão 3D oferece amplas possibilidades de personalização dos produtos, permitindo se chegar muito mais próximo à voz dos clientes. Na execução da atividade de modelagem, notou-se que é fundamental evitar o desperdício de material, culminando em um menor custo e tempo de produção. Caso seja necessário realizar cortes no produto para a impressão tridimensional, recomenda-se que o menor número de cortes seja realizado posicionando as peças de forma que estas tenham equilíbrio e as rotacionando, caso esta prática apresente uma melhor posição na base de impressão. Para a destinação correta dos resíduos gerados (estruturas para a sustentação da impressão), sugere-se a aquisição de uma máquina extrusora que os transforma novamente em filamento. Na elaboração do projeto detalhado, a análise de viabilidade deve se basear nos cálculos apresentados pelo software fatiador de tempo para impressão e quantidade de filamento a ser utilizada, entre outros fatores como, por exemplo, quantidade de energia requerida.

Ao invés da denominação da fase de produção, optou-se por chamá-la de impressão devido à particularidade desta forma de produção. Sugere-se ainda a realização de acabamentos próprios desta tecnologia. As atividades de homologação e validação foram unidas em apenas uma e nela foram previstos a realização de testes de qualidade no produto impresso. A pós-produção ficou denominada 
como pós-impressão seguindo essa linha de raciocínio. Acrescentou-se a atividade de descontinuação do produto prevendo a grande agilidade de criação de novos produtos impressos tridimensionalmente.

\subsubsection{Modelagem e impressão do sapato de salto alto.}

A impressão do sapato de salto alto foi realizada simultaneamente com a elaboração do modelo de referência como prova de conceito a fim de proporcionar contribuições ao modelo que chegou ao seu formato final ilustrado na Figura 1. Dentre as contribuições estão: priorização na voz do cliente, resiliência nó método de produção, inserção do conceito de produção mais limpa com foco na minimização de desperdícios. Para a prova de conceito, o sapato de salto foi desenvolvido a partir de modelagens tridimensionais prontas disponíveis em um website de downloads tridimensionais. Esses downloads vêm com uma licença para utilização e comercialização, entretanto, é necessário dar créditos ao desenvolvedor. Desta forma, dois downloads foram realizados: o de um salto alto desenvolvido por Iren Vartik ${ }^{\ddagger}$ e o de uma raposa para constituir um detalhe no salto alto desenvolvido por Victor Tereshchenko ${ }^{\S}$.

Entretanto, a modelagem destes downloads não é específica para a impressão 3D, portanto, foi preciso realizar alterações até que a modelagem pudesse ser impressa, tais como: posicionamento do sapato, exclusão de um pé, modificações estéticas, exclusão da palmilha, aumento do comprimento do salto, entre outras. A Figura 2 retrata diversos ângulos do sapato desenvolvido.
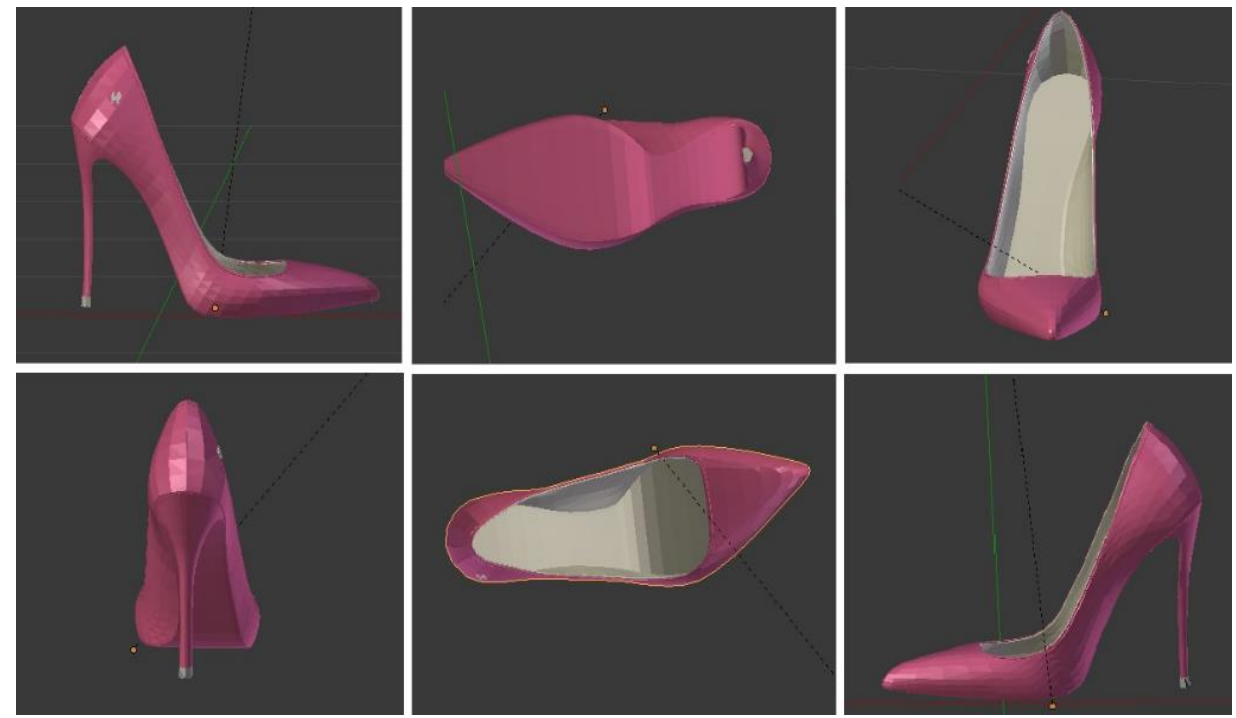

Figura 2 - Modelagem no software Blender em vários ângulos

Fonte: autoria própria (2017)

Uma das limitações da impressora disponível foi seu tamanho de impressão. As dimensões de impressão da impressora são 140 x 140 x 135 mm. Portanto, foi necessário realizar cortes na modelagem original (Figura 3).

\footnotetext{
thttps://yobi3d.com/v/ipN6bKxNIZ/Shoes-IREN-VARTIK-N141116.3DS

${ }^{8}$ http://youmagine.com/designs/fox-keychains
} 

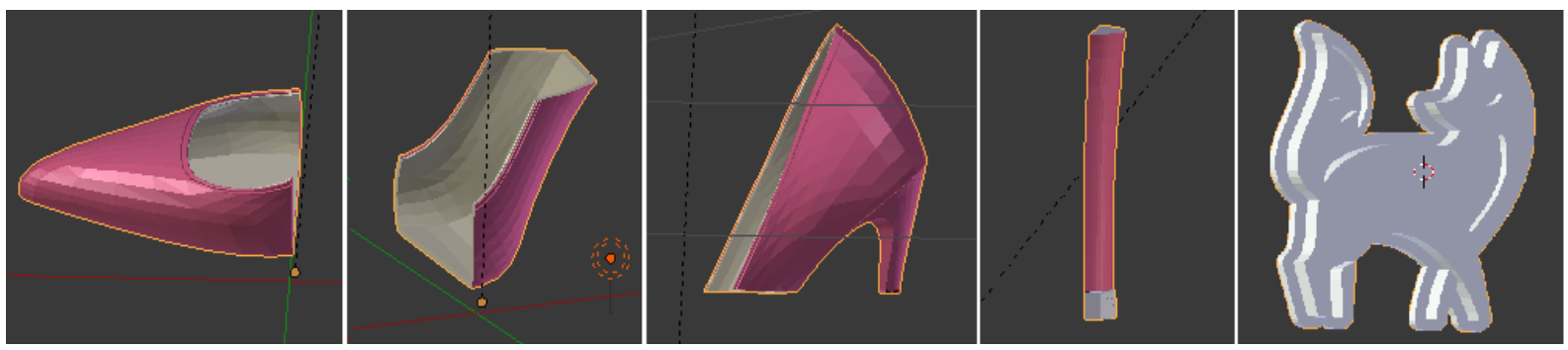

Figura 3 - Partes da modelagem do sapato enviadas para a impressão

Fonte: autoria própria (2017)

Esses cortes na modelagem foram realizados considerando a estrutura de cada parte a ser impressa, evitando o desperdício de filamento com suportes na hora da impressão e intencionando a menor quantidade de cortes possíveis. A raposa teve seu tamanho aumentado em relação às demais partes do salto alto para possibilitar melhor visualização, mas sua dimensão para a impressão foi de 1 $\mathrm{cm}$. Uma vez realizados os cortes na modelagem e exportados em arquivos separados, cada parte foi importada para o software fatiador e então enviada para a impressão. O tempo de impressão e quantidade de filamento utilizada do bico do sapato, junção ao bico, junção ao salto, salto e detalhe de raposa, foram dispostos na Tabela 1.

Em relação as condições de impressão, destaca-se que, para a impressão das partes, a temperatura de extrusão foi de $260^{\circ} \mathrm{C}$ e a temperatura da mesa em $100^{\circ} \mathrm{C}$. Além disso, é importante destacar que o ambiente em que foi realizada a impressão é climatizado e a temperatura foi mantida em $19^{\circ} \mathrm{C}$. O limite de contração considerado para o projeto é de $5 \%$, dado o material utilizado que é o ABS.

Tabela 1 - Tempo de impressão e quantidade de filamento

\begin{tabular}{ccc}
\hline PARTES & TEMPO DE IMPRESS ̃̃O $(\mathbf{m})$ & $\begin{array}{c}\text { QUANTIDADE DE } \\
\text { FILAMENTO }\end{array}$ \\
\hline Bico do sapato & $3 \mathrm{~h} 20 \mathrm{~m} 22 \mathrm{~s}$ & $41,32 \mathrm{~g}$ \\
Junção ao bico & $2 \mathrm{~h} 14 \mathrm{~m} 7 \mathrm{~s}$ & $24,31 \mathrm{~g}$ \\
Junção ao salto & $3 \mathrm{~h} 54 \mathrm{~m}$ & $37,4 \mathrm{~g}$ \\
Salto & $51 \mathrm{~m} 12 \mathrm{~s}$ & $6,91 \mathrm{~g}$ \\
Detalhe de raposa & $8 \mathrm{~m} 34 \mathrm{~s}$ & $0,51 \mathrm{~g}$ \\
TOTAL & $\mathbf{1 0 h 2 8 m 4 7 s}$ & $\mathbf{1 1 0 , 4 5}$ \\
\hline
\end{tabular}

Fonte: autoria própria (2017)

A Figura 4 retrata todas as partes do sapato impressas. 


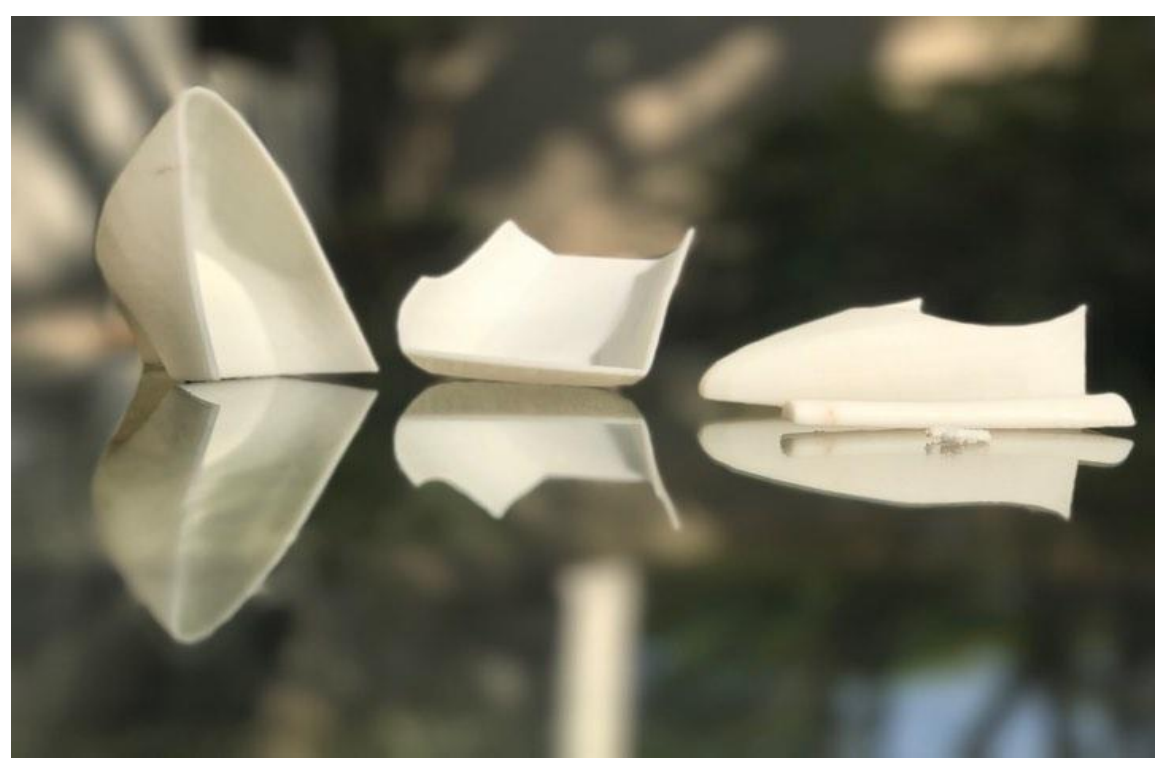

Figura 4 - Peças impressas do salto alto Fonte: autoria própria (2017)

Uma vez que as peças apresentaram um encaixe perfeito, efetuou-se a colagem das partes com uma cola superbonder. Na Figura 5 é possível visualizar o sapato pronto.

A cola superbonder não se mostra eficiente para a junção permanente das peças. Um ajuste necessário no processo de desenvolvimento seria a inserção de impressão tipo "lego", o que proporcionaria um alívio nos pontos de tensão e maior superfície de contato para a adesão entre as partes. Outra opção é a utilização de uma caneta tridimensional, mas após a utilização desta, uma série de acabamentos para o resultado estético desejado precisa ser realizada. Esta alternativa não foi realizada no salto alto impresso devido à ausência deste equipamento.

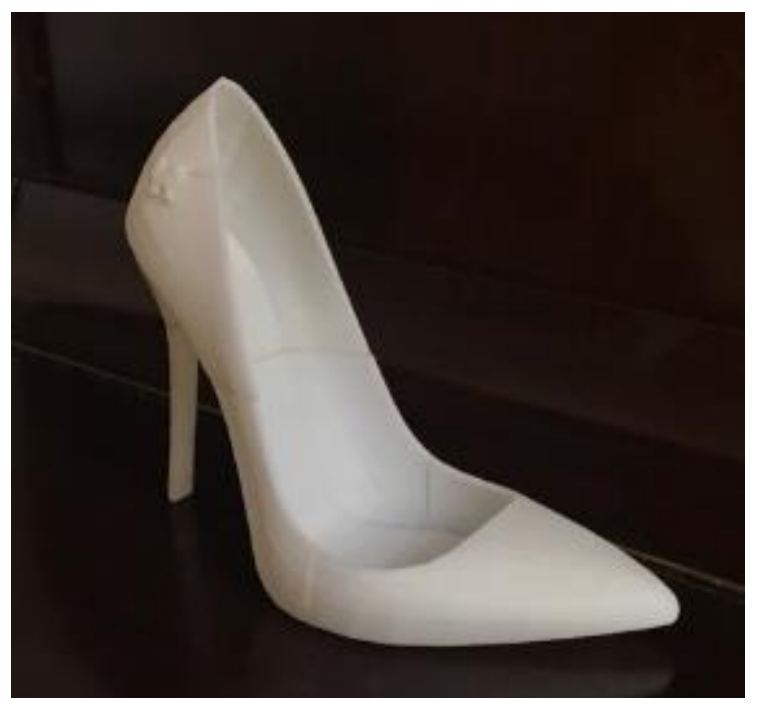

Figura 5 - Protótipo de Salto Alto Impresso 3D

Finalmente, é necessário explicar que o sapato, embora tendo as proporções de um sapato comum, não calça o número 37 ao qual ele foi projetado. Isso ocorre devido a sua dureza. O preenchimento do material na impressão (infill) foi acima de $90 \%$ o que tornou o material muito duro. A utilização do material ABS, embora tenha demonstrado não ter sido o ideal, mostrou-se viável para a impressão de protótipos, proporcionando maiores detalhes e realismo para a tomada de decisão de estilistas. A partir 
dela, por exemplo, foi possível identificar algumas necessidades para a modelagem de um sapato tridimensional, como a estipulação da dureza na seleção do filamento mais adequado, e porcentagem de seu preenchimento, em que, deve haver a busca por mecanismos para aumentar o conforto e rupturas fornecendo a possibilidade de ser calçado. O modelo é uma proposta inicial que pode ser utilizada como base para pesquisas futuras no desenvolvimento de produtos em impressoras 3D. É importante ressaltar que ao utilizar a impressão 3D na moda os parâmetros de impressão, tais como temperatura do bico, temperatura do leito de impressão e orientação do enchimento, exercem um grande impacto, conforme apontado por Spahiu, Canak e Shehi (2020).

A prova de conceito demonstrou que desenvolver um produto para impressão em 3D não significa somente criar e imprimir, mas sim guiar esse por meio de uma sequência de etapas todo processo de desenvolvimento de produtos seguindo essa nova proposta alinhada com a indústria 4.0.

\section{Considerações Finais.}

A impressão 3D é uma tecnologia que altera significativamente o método de produção tradicional fornecendo ferramentas de produção extraordinárias. Entretanto, ainda há limitações para esta tecnologia que variam de impressora para impressora, mas em um modo geral ainda têm muito a evoluir. Algumas perspectivas de melhoria são o tempo de impressão, quantidade de materiais, cores disponíveis de impressão, entre outras possibilidades.

Desta forma, com a perspectiva de aumento de utilização desta tecnologia por uma indústria como a da moda, a utilização de um modelo de referência específico ao ramo prefigura uma grande utilidade ao desenvolvimento de produtos do vestuário. A impressão do sapato de salto alto, embora com falhas em seu projeto, contribuiu muito para a proposta do modelo de PDPVI3D.

A respeito da criação do modelo de referência a partir de outros modelos, houve dificuldade em comparação entre as atividades presentes nas fases dos modelos, pois atividades similares foram classificadas em fases diferentes pelos distintos autores. Entretanto, devido ao número e a relevância dos modelos selecionados o modelo proposto se apresentou como bastante completo.

Os cálculos automáticos realizados pelo software fatiador de tempo de impressão e quantidade de filamento utilizada permitem que os cálculos de viabilidade sejam realizados facilmente. Atualmente, para a maioria dos setores a impressão 3D se mostra vantajosa financeiramente apenas para produtos personalizados ou para a prototipagem, pois as tecnologias de produção de larga escala ainda apresentam menor custo. Entretanto, com o crescimento da tecnologia de impressão 3D isto tende a mudar.

A prova de conceito demonstrou que o modelo proposto pode contribuir para o desenvolvimento e impressão de produtos $3 \mathrm{D}$ por ser um produto novo no mercado e com fortes indícios de crescimento. Com isso, nota-se que o modelo proposto de PDPVI3D contribui muito para indústria principalmente para a prototipagem ou impressão de produtos finais personalizados, mas também prevê o aumento da tecnologia em que poderá ser utilizada mais futuramente com a produção em larga escala ou ainda com a venda de downloads da modelagem dos produtos para serem impressos pelos próprios clientes em suas casas ou em qualquer impressora que estes tiverem acesso.

Vale ainda ressaltar que, quando a venda de downloads tridimensionais prontos para a impressão se tornar realidade, a logística terá seu local apenas no transporte das matérias primas e haverá grandes rupturas na forma de produção atual, sendo possível a eliminação de fábricas completas ou de inúmeros setores das mesmas. Isso enfatiza ainda mais a relevância histórica contínua do processo de desenvolvimento de produtos e dos modelos de referência que vão sendo atualizados, assim como sua essencialidade para as organizações.

Ainda é importante ressaltar que atualmente estamos à beira da quarta revolução tecnológica, conhecida como a Indústria 4.0. Esta revolução provocará modificações intensas nos arranjos sociais, 
econômicos e políticos e unirá cada vez mais o meio físico e biológico ao digital, tornando o emprego de pessoas com pouco conhecimento agregado e com funções repetitivas cada vez mais defasado. Desta forma, é relevante mencionar que o modelo de referência PDPVI3D permanecerá completamente apto para ser inserido nas organizações nesta nova configuração industrial.

Assim sendo, este modelo contribui academicamente com a incorporação desta inovação radical, a tecnologia de impressão 3D, ao processo de desenvolvimento de produtos. Colabora também com a proposta de um novo modelo de referência, o PDPVI3D, e coopera ainda, com a descrição dos resultados negativos e positivos do sapato impresso.

Em relação a impressão do salto alto, nota-se sua contribuição para futuras impressões de itens do vestuário. Verifica-se também com esta impressão o quão simples a produção de um item que, originalmente apresenta diversas etapas de produção no método de produção tradicional, pode agora ser realizada. Percebe-se ainda que a criação de novos formatos de vestuários inovadores passa a ser possível e, além disso, uma exploração de uma gama de novos materiais, texturas, entre muitos outros aspectos.

Como oportunidades para trabalhos futuros destaca-se um estudo da tecnologia de medição das partes do corpo humano para o desenvolvimento de produtos do vestuário impressos tridimensionalmente, o estudo de configurações e estampas viáveis para a impressão 3D de vestuários, a validação do modelo de referência PDPVI3D e também pesquisas a respeito da própria utilização destes itens do vestuário por usuários.

\section{Referências.}

AMZA, C.; ZAPCIU, A.; POPESCU, D. 3D-Printed shoe last for bespoke shoe manufacturing. 9Th International Conference on Manufacturing Science and Education - MSE 2019 "Trends in New Industrial Revolution, 2019.

ANDRADE, N. R. A. F. O papel do design no desenvolvimento de calçados. Dobras, v.6, n.13, 2013.

AUER, T. Mittel und Strategien für die Integration des Kunden bei der Neuproduktentwicklung. Handlungempfehlungen im Bereich der Mass Customization. Medien: Studienarbeit, 2016.

AVRAHAM, S. New product development: Experience from Distance Learning and Simulation-Based Training. Scientific Research Publishing: Creative Education, v.7, p.105-113, 2016.

BACK, N; OGLIARI, A; DIAS, A; SILVA, J. Projeto integrado de produto: planejamento, concepção e modelagem. Barueri, São Paulo: Manole, 2008.

BARBALHO, S. C. M; ROZENFELD, H. Modelo de referência para o processo de desenvolvimento de produtos mecatrônicos (MRM): validação e resultados de uso. Gestão \& Produção. UFSCAR: Impresso, v.20, p.162-179, 2013.

BAXTER, M. Projeto de produto: guia prático para o design de novos produtos. São Paulo: BLucher, 3.ed. 2011.

BERMAN, B. 3D printing: The new industrial revolution. Elselvier: Business Horizons, v.55, p.155$162,2012$.

BIRTCHNELL, T; URRY, J. 3D, SF and the future. Elselvier: Futures, v.50, p.25-34, 2013.

BORNIA, A. C; LORANDI, J. A. O processo de desenvolvimento de produtos compartilhado na cadeia de suprimentos. Curitiba: Revista FAE, v.11, n.2, p.35-50, 2008.

BOUNCKEN, R. B; FREDRICH, V; RITALA, P; KRAUS, S. Coopetition in new product development alliances: advantages and tensions for incremental and radical innovation. British Journal of Management, 2017. 
CAUTELA, C; PISANO, P; PIRONTI, M. The emergence of new networked business models technology innovation: an analisys of 3D printing design enterprises. International Entrepreneurship and Management Journal, v.10, p.487-501, 2014.

CORRAL, L. C; WALKER, K. J. Exploring the abilities of 3D printing and its viability for consumption in the fashion industry. Apparel Merchandising and Product Development Undergraduate Honors Theses, 2017.

FASTERMANN, P. 3D Drucken. Wie die generative Fertigungstechnick funktioniert. Springer: Krefeld: Alemanha, 2016.

GEBLER, M; UITERKAMP, A. J. M. S; VISSER, C. A global sustainability perspective on 3D printing technologies. Elselvier: Energy Policy, v.74, p.158-167, 2014.

GRAIN, E; UNVER, E. 3D Printed Fashion: A Dual Approach. Interdisciplinary Conference, Oxford University, 2016.

GRIFFIN, A; VOJAK, B; PRICE, R; HOFFMAN, N. Serial Inovators' processes: How they overcome barriers to creating radical innovations. Industrial Marketing Manegement, v.43, p.1362-1371, 2014.

HART, S. New product development. In: BAKER, M. J; HARTTT, S. The Marketing Book. Abinddon and New York: Routledge, p.314-336, 2016.

HU, C; JUN, C; FOLEY, M. Valuating new product development project with a stochastic volatility model. Journal of Mathematical Finance, v.6, p.975-1001,2016.

KUESTER, S; DEKER, J; SCHUMACHER, M. Ist die zusammenarbeit mit externen kooperationpartnern in der Neuproduktentwicklung erfolgreich? - Eine Meta-Analyse. Institut für Marktorientierte Unternehmensführung: Kompetenz in Wissenchaft \& Management, 2016.

KUMAR, L; KUMAR, V; HALEEM, A. Rapid prototyping technology for new product development. International Journal of Innovative Science, Engineering \& Technology, v.3, 2016.

LIMA, B. L; JACQUES, J. J; PIZZATO, G. Z. A; LINDEN, J. C. S; RUTHSCHILING, E. A. Proposta de diretrizes no modelo de processo de desenvolvimento de produto (pdp) para a moda ética. In: BERNARDES, M. M. S; LINDEN, J. C.S. Design em Pesquisa. Porto Alegre: Marcavisual, v.1, p.235253, 2017.

MARQUES, C. A. N; MENDES, G. H. S; OLIVEIRA, M. G; ROZENFELD, H. Comparing PSS design models based on content analysis. Science Direct, 2016.

MONTES, J. O. Impacts of 3D printing on the development of business models. Technology and Service Complementarity in Industry 4.0, 2016.

MORETTI, I. C; BRAGHINI, J. A. Reference model for apparel product development. Independet Journal of Management \& Production, v.8, p.232-262, 2017.

NGO, T. D.; KASHANI, A.; IMBALZANO, G.; NGUYEN, K. T. Q. Additive manufacturing (3D printing): A review of materials, methods, applications and challenges. Composites Part B: Engineering, v. 143, n. 15 , p. $172-196,2018$.

PAULA, J. F; MELLO, C. H. P. Seleção de um modelo de referência de PDP para uma empresa de autopeças através de um método de auxílio à decisão por múltiplos critérios. Production, v.23, n.1, 2012.

PRODANOV, C. C; FREITAS, E. C. Metodologia do trabalho científico: métodos e técnicas da pesquisa e do trabalho acadêmico. Novo Hamburgo, Rio Grande do Sul: Universidade Feevale, 2013.

RAYNA, T; STRIUKOVA, L. From rapid prototyping to home fabrication: How 3D printing is changing business model inovation. Elselvier: Technological Forecasting \& Social Change, p.214-224, 2016. 
SANTIS, S. H. S; DEDINI, F. G; MARCICANO, J. P. P; SANCHES, R. A; HELD, M. S. B; FORNAZZARI, L. B; SANTIS, V. C. Strategy of textile design: Use of design methodology tools in the creative process. Strategic Design Research Journal, v.10, p.57-66, 2017.

KIM,Y.-S., JUN,Y.-S.,PARK,K.-J.AND KIM, J.-H. Formative characteristics of women's shoes design utilizing 3D printing technology. Journal of the Korean Society of Costume, v. 66, n. 9, p. 14-32, 2016.

KOSTYLEVA, V. V.; KONOVALOVO, O. B. Concept of parametric design and fast 3D printing of individual shoes. International Scientific Journal Industry 4.0, v. 5, n. 2, p. 72-5, 2020.

PARK, J.; LEE, J. A Study on the Customization of Shoes Design Characteristics with 3D Printing Technology 3D. Proceedings of the Korean Institute of Information and Commucation Sciences Conference, p. 516-517, 2019.

PERRY, A. 3D-printed apparel and 3D-printer: exploring advantages, concerns, and purchases, International Journal of Fashion Design, Technology and Education, v. 11, n. 1, p. 95-103, 2017.

SHIH, T. Y. Determinants of Enterprises Radical Innovation and Performance: Insights into Strategic Orientation of Cultural and Creative Enterprises.Sustainability, v. 10, 1871, 2018.

SPAHIU, T.; CANAJ, R.; SHEHI, E. 3D Printing for clothing production. Journal of Engineered Fibers and Fabrics, v. 15, n. 1, 2020.

SPAHIU T.; PIPERI E.; EHRMANN A.; ALMEIDA H.A.; ASCENSO R.M.T.; VITORINO L.C. (2020) 3D Printing: An Innovative Technology for Customised Shoe Manufacturing. In: Almeida H., Vasco J. (eds) Progress in Digital and Physical Manufacturing. ProDPM 2019. Lecture Notes in Mechanical Engineering. Springer, Cham. https://doi.org/10.1007/978-3-030-29041-2_22

SNYDER, H.; WITELL, L.; GUSTAFSSON, A.; FOMBELLE, P.; KRISTENSSON, P. Identifying categories of servisse innovation: a review and synthesis of the literature. Journal of Business Research, v.69, p.2401-2408, 2016.

SOUZA, A. J. S. Desgin como forma de inovação no processo de desenvolvimento de produtos (PDP) e seus conceitos metodológicos. DI Factum, 2016.

TAPIA, C. Análisis comparativo de prendas y estructuras textiles realizadas por impresión 3D. Buenos Aires, Argentina: SIGraDi, XX Congreso de la Sociedad Ibero-americana de Gráfica Digital, 2016.

TARICHI, A. P; AMARAL, C. S. T; FRIAS, D. F. R; RODRIGUES, R. Modelo de referência para desenvolvimento de novos produtos: sugestões para pesquisas no setor de biotecnologia. Revista Unifev: Ciência e Tecnologia, v.1, n.1, 2016.

TREPTOW, D. Inventando moda: planejamento de coleção. São Paulo: Saraiva, 2013.

UNITED NUDES. Collection Of Scultural Shoes From Design Fashion Week 2015, April, 2015. Disponível em: https://ashadedviewonfashion.com/2015/04/17/united-nude-collection-scultural-shoesdesign-fashion-week-2015/.

VANDERPLOEG, A.; LEE, S.; MAMP, M. The application of 3D printing technology in the fashion industry. International Journal of Fashion Design, Technology and Education, v. 10, n. 2, p. 170-179, 2017. 